\title{
RESISTÊNCIA DE ACESSOS DE MELANCIA AO PULGÃO Aphis gossypii glover (H emiptera: Aphididae) NO ESTADO DE RORAIMA, BRASIL
}

\author{
Resistanœ of watermelon line sources to Aphis gossypii Glover \\ (H emiptera: A phididae) in the State of Roraima, Brazil
}

\author{
Alberto Luiz Marsaro Júniora, Paulo Roberto Valle da Silva Pereirab, Moisés Mourão Júnior \\ a Entomologista, E mbrapa Roraima, Boa Vista, RR - Brasil, e-mail: alberto@ cpafrr.embrapa.br \\ ${ }^{\text {b }}$ Entomologista, E mbrapa Trigo, Passo Fundo, RS - Brasil, e-mail: paulo@ cnpt.embrapa.br \\ c Bioestatístico, Embrapa Amazônia O riental, Belém, PA - Brasil, e-mail: mmouraojr@ gmail.com
}

\section{Resumo}

A resistência de acessos de melancia foi avaliada com relação à infestação pelo pulgão A phis gossypii em casa de vegetação no Estado de Roraima. Sementes de 29 acessos de melancia foram plantadas em vasos dispostos de maneira casualizada. A pós o desbaste deixou-se uma única planta, com duas folhas completamente desenvolvidas, por vaso. Com o auxílio de um pincel colocou-se uma fêmea adulta áptera em cada uma das folhas. A seguir, cada fêmea foi confinada numa gaiola individual coberta com tela antiafídio. Vinte e quatro horas após o confinamento avaliou-se o número de ninfas geradas por fêmea. Realizou-se um total de 24 repetições para cada acesso de melancia. Os dados foram submetidos à análise de variância e as médias comparadas pelo teste de $\mathrm{D}$ uncan em $5 \%$. O s acessos de melancia apresentaram diferentes graus de resistência com relação ao pulgão A . gossypii. $\mathrm{O}$ acesso mais suscetível, ou seja, o que propiciou um maior número de descendentes após 24 horas de alimentação das fêmeas (8,17 ninfas) foi o de número 13. O s mais tolerantes, que apresentaram os menores números de descendentes, foram os acessos 2; 10 e 25, com 4,17; 4,08 e 3,50 ninfas, respectivamente.

Palavras-chave: Resistência de plantas a insetos. Manejo integrado de pragas. Afídeos.

\section{Abstract}

The resistance of watermelon line sources to Aphis gossypii infestations was evaluated in greenhouse condition in the state of Roraima. Seeds of 29 watermelon line sources were cultivated in pots randomly distributed. After germination only one plant with two leaves completely developed was left by pot. With a fine brush one apterous female were placed in each leaf and individually confined in an aphid cage. Twenty four hours after confinement the number of nymphs/female was counted. To each line source 24 replicates were done. The data obtained 
were submitted to analysis of variance and means compared by Duncan Test, at the level of 5\%. The watermelon line sources showed different levels of resistance to Aphis gossypii infestations. The most susceptible, with the higher number of nymphs/female after 24 hours (8.17 nymphs), was number 13. The most tolerant, showing lower number of nymphs/female, were the line sources 2; 10 e 25, with 4.17, 4.08 and 3.50 individuals, respectively.

Keywords: Plant resistance to insect. Integrated pest management. Aphids.

\section{INTRODUÇÃO}

A melancia é uma das alternativas de exploração agrícola para as áreas de cerrado e de mata em Roraima, devido à adaptação da cultura às condições agroclimáticas da região, aliada à boa aceitação dos frutos no mercado local e ao rápido retorno econômico (ciclo em torno de 70 dias), quando comparado ao de outras culturas. Essas características têm despertado grande interesse dos produtores pelo cultivo dessa fruta no estado (MEDEIRO S; ALVES, 2007).

A produtividade média da cultura no Estado é estimada em 20.000 kg.ha-1 (ALVE S, 2007). Essa produtividade poderia ser maior, porém a presença de insetos-praga na cultura contribui para a redução da produção. Em Roraima, já foram relatados os seguintes insetos ocasionando danos na cultura da melancia: A phis gossypii, Myzus persicae, Bemisia tabaci, Thrips tabaci, Thrips palmi, D iaphania hyalinata, D iaphania nitidalis, D iabrotica speciosa, A tta sex dens rubropilosa e L iriomyza sp. (MARSARO Jr.; PEREIRA; MOREIRA, 2007).

D entre os insetos que causam danos, destaca-se como um dos principais da cultura da melancia no Estado o pulgão A . gossypii. Esse inseto, em função de seu aparelho bucal do tipo sugador, se alimenta da seiva das plantas, provoca deformações nas folhas, brotos e ramos, causando encarquilhamento e enrolamento das folhas e gemas apicais, e reduz a capacidade fotossintética das plantas atacadas (PEREIRA; NASCIMENTO; DIAS, 2002).

Além dos danos diretos, esse pulgão pode transmitir viroses para a cultura. A infecção viral pode ocasionar perdas significativas, em função da redução do limbo foliar, enfezamento, deformação dos frutos e alteração de sua coloração. Sintomas do vírus PRSV-W (da mancha-anelar-do-mamoeiro - estirpe melancia) e do vírus ZYMV (do mosaico-amarelo-da-abobrinha) já foram observados em Roraima em plantas com infestação de pulgões (HALFELD-VIEIRA et al., 2004).

O utro dano indireto ocorre em razão da eliminação de substâncias excretadas pelos pulgões sobre as folhas, o que favorece o desenvolvimento do fungo Capnodium sp., conhecido como fumagina, o qual reveste as folhas da planta, dificultando, assim, a respiração e a fotossíntese, e contribuindo para 0 enfraquecimento da planta (PEREIRA; NASCIMENTO; DIAS, 2002).

Estudos conduzidos por Pereira et al. (2003) demonstraram que a aplicação de inseticidas sistêmicos no controle de A . gossypii não reduziu a incidência de viroses na cultura da melancia. Diante disso, é importante a busca por outros métodos de controle que possam auxiliar no manejo desse pulgão nessa cultura.

O uso de plantas resistentes a insetos é uma estratégia importante no Manejo Integrado de Pragas (MIP) e pode ser adotado juntamente com outros métodos de controle, sejam químicos ou biológicos.

No Brasil, alguns estudos já realizados com o objetivo de avaliar a resistência de plantas ao ataque de A. gossypii demonstraram que existem genótipos que afetam negativamente aspectos biológicos desse pulgão. Nesses estudos as plantas avaliadas foram o crisântemo (SO G LIA; BUENO; SAMPAIO, 2002) e algodão (FERNANDES et al., 2001; MICHELOTTO; SILVA; BUSO LI, 2003).

São raros, no Brasil, estudos que visam avaliar a resistência de genótipos de melancia aos pulgões associados com essa cucurbitácea. Nesse sentido, esse trabalho teve por objetivo avaliar a resistência de acessos de melancia ao pulgão A . gossypii no Estado de Roraima. 


\section{MATERIAIS E MÉTODOS}

Este trabalho foi realizado em casa de vegetação na Embrapa Roraima. Sementes de 29 acessos de melancia, cedidas pela E mbrapa Semi-Árido, foram plantadas em vasos, de aproximadamente $10 \mathrm{~kg}$, dispostos de maneira casualizada.

A pós o desbaste deixou-se uma única planta, com duas folhas completamente desenvolvidas, por vaso. Com o auxílio de um pincel fino colocou-se uma fêmea adulta áptera em cada uma das folhas. A seguir, cada fêmea foi confinada numa gaiola individual coberta com tela antiafídeo à semelhança do método proposto por Vendramim e Nakano (1981). Vinte e quatro horas após o confinamento avaliouse o número de descendentes, ou seja, de ninfas geradas por fêmea conforme metodologia empregada em Michelotto, Silva e Busoli (2003).

Realizou-se um total de 24 repetições para cada acesso de melancia. Os dados foram submetidos à análise de variância e as médias comparadas pelo teste de D uncan em 5\%.

\section{RESULTADOS}

O bserva-se na Tabela 1 e Figura 1 que os acessos de melancia apresentaram diferentes graus de resistência com relação ao pulgão A . gossypii. 0 acesso mais suscetível, ou seja, o que propiciou um maior número de descendentes após 24 horas de alimentação das fêmeas (8,17 ninfas) foi o de número 13. Os mais tolerantes, que apresentaram os menores números de descendentes, foram os acessos 2,10 e 25, com 4,17; 4,08 e 3,50 ninfas, respectivamente. Os demais acessos apresentaram resistência intermediária entre esses dois grupos.

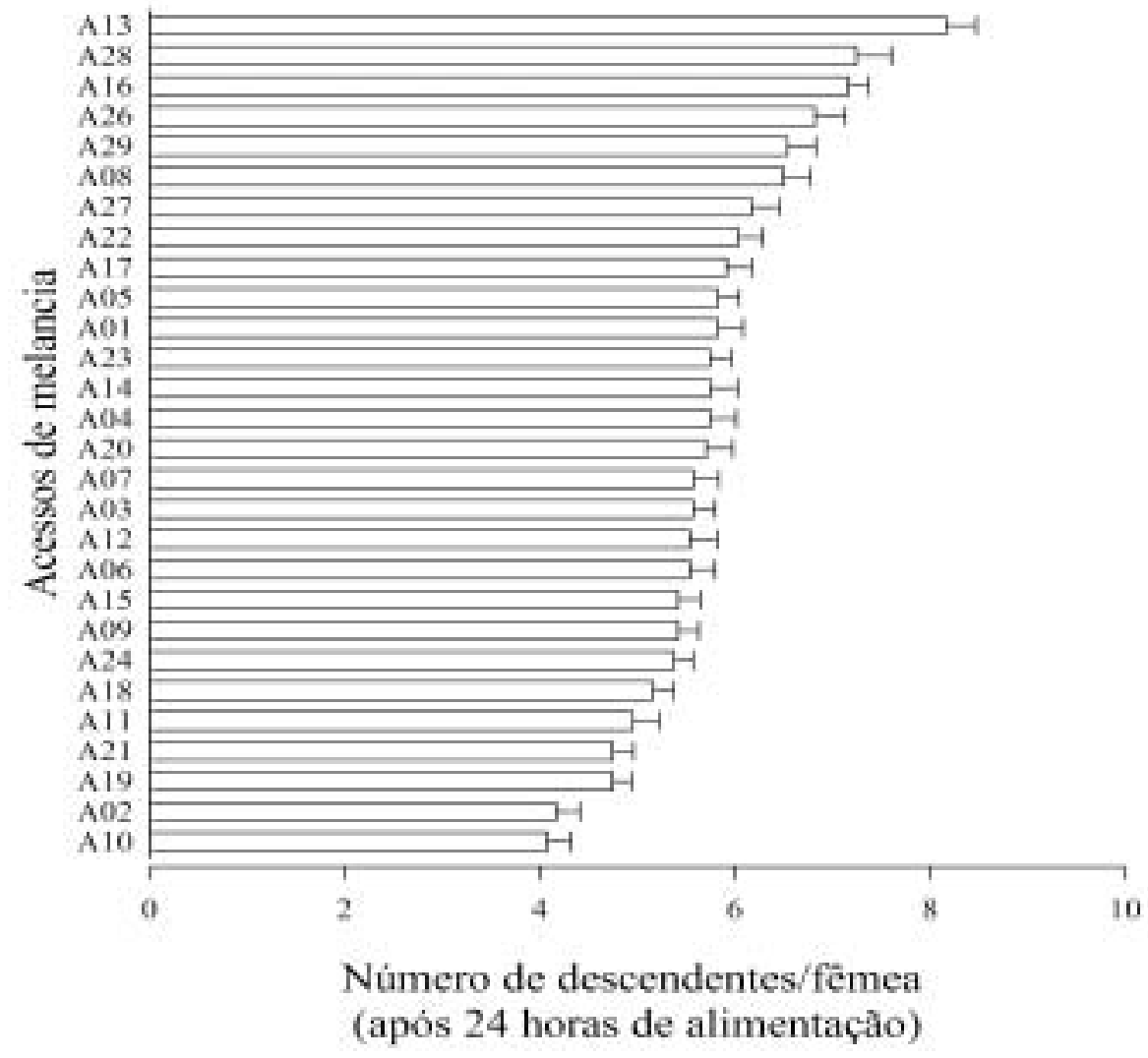

FIGURA 1 - Número médio de descendentes \pm erro-padrão (EP) após 24 horas de alimentação de fêmeas de A phis gossypii em diferentes acessos de melancia 
TABELA 1 - Número médio de descendentes \pm erro-padrão (EP) após 24 horas de alimentação de fêmeas de A phis gossypii em diferentes acessos de melancia

\begin{tabular}{|c|c|c|c|c|c|c|c|c|c|c|c|c|}
\hline $\begin{array}{l}\text { Acessos } \\
\text { de } \\
\text { melancia }\end{array}$ & $\begin{array}{l}\text { Número de } \\
\text { descendente } \\
\quad \pm \text { EP* }\end{array}$ & & & & & & & & & & & \\
\hline A13 & $8,17 \pm 1,46$ & $\mathrm{a}$ & & & & & & & & & & \\
\hline A28 & $7,25 \pm 1,70$ & & $\mathrm{~b}$ & & & & & & & & & \\
\hline A 16 & $7,17 \pm 1,01$ & & $\mathrm{~b}$ & & & & & & & & & \\
\hline A26 & $6,83 \pm 1,46$ & & $\mathrm{~b}$ & $\mathrm{C}$ & & & & & & & & \\
\hline A29 & $6,54 \pm 1,41$ & & $\mathrm{~b}$ & $\mathrm{C}$ & $\mathrm{d}$ & & & & & & & \\
\hline A08 & $6,50 \pm 1,32$ & & $\mathrm{~b}$ & $\mathrm{C}$ & $\mathrm{d}$ & $\mathrm{e}$ & & & & & & \\
\hline A27 & $6,17 \pm 1,37$ & & & $\mathrm{C}$ & $\mathrm{d}$ & e & $\mathrm{f}$ & & & & & \\
\hline A22 & $6,04 \pm 1,20$ & & & & $d$ & e & $\mathrm{f}$ & & & & & \\
\hline A 17 & $5,92 \pm 1,21$ & & & & $d$ & e & $\mathrm{f}$ & g & & & & \\
\hline A05 & $5,83 \pm 1,05$ & & & & $d$ & e & $\mathrm{f}$ & $\mathrm{g}$ & & & & \\
\hline $\mathrm{A} 01$ & $5,83 \pm 1,24$ & & & & $d$ & e & $\mathrm{f}$ & g & & & & \\
\hline A23 & $5,75 \pm 1,03$ & & & & $\mathrm{~d}$ & e & $\mathrm{f}$ & g & $\mathrm{h}$ & & & \\
\hline A14 & $5,75 \pm 1,33$ & & & & $\mathrm{~d}$ & e & $\mathrm{f}$ & $\mathrm{g}$ & $\mathrm{h}$ & & & \\
\hline $\mathrm{A} 04$ & $5,75 \pm 1,29$ & & & & $d$ & $\mathrm{e}$ & $\mathrm{f}$ & $g$ & $\mathrm{~h}$ & & & \\
\hline A20 & $5,71 \pm 1,30$ & & & & & $\mathrm{e}$ & $\mathrm{f}$ & $g$ & $\mathrm{~h}$ & & & \\
\hline $\mathrm{A} 07$ & $5,58 \pm 1,25$ & & & & & & $\mathrm{f}$ & $g$ & $\mathrm{~h}$ & & & \\
\hline A03 & $5,58 \pm 1,06$ & & & & & & $\mathrm{f}$ & $\mathrm{g}$ & $\mathrm{h}$ & & & \\
\hline A 12 & $5,54 \pm 1,35$ & & & & & & $\mathrm{f}$ & $g$ & $\mathrm{~h}$ & i & & \\
\hline A06 & $5,54 \pm 1,25$ & & & & & & $\mathrm{f}$ & $\mathrm{g}$ & $\mathrm{h}$ & $\mathrm{i}$ & & \\
\hline A15 & $5,42 \pm 1,10$ & & & & & & $\mathrm{f}$ & $g$ & $\mathrm{~h}$ & i & & \\
\hline A09 & $5,42 \pm 1,02$ & & & & & & $\mathrm{f}$ & $\mathrm{g}$ & $\mathrm{h}$ & i & & \\
\hline A24 & $5,38 \pm 0,92$ & & & & & & $\mathrm{f}$ & $g$ & $\mathrm{~h}$ & i & & \\
\hline A18 & $5,17 \pm 0,96$ & & & & & & & $g$ & $\mathrm{~h}$ & i & & \\
\hline A11 & $4,96 \pm 1,30$ & & & & & & & & $\mathrm{~h}$ & i & & \\
\hline A21 & $4,75 \pm 1,03$ & & & & & & & & & i & $\mathrm{j}$ & \\
\hline A19 & $4,75 \pm 0,94$ & & & & & & & & & i & j & \\
\hline A02 & $4,17 \pm 1,17$ & & & & & & & & & & $\mathrm{j}$ & $\mathrm{k}$ \\
\hline A10 & $4,08 \pm 1,14$ & & & & & & & & & & $j$ & $\mathrm{k}$ \\
\hline A25 & $3,50 \pm 1,10$ & & & & & & & & & & & $\mathrm{k}$ \\
\hline
\end{tabular}

*Valores precedidos de mesma letra, na vertical, não diferem significativamente, segundo o teste de Duncan, no nível de significância de 5\%.

A resistência de plantas a insetos pode ser atribuída a diversos fatores: físicos (radiações), químicos (alcalóides, compostos antinutricionais e outros) e morfológicos (rigidez de tecidos, pilosidade e outros) (LARA, 1991).

Soglia, Bueno e Sampaio (2002), ao avaliarem o desenvolvimento de ninfas de A . gossypii submetidas a três cultivares de crisântemo, verificaram que nas cultivares White Reagan e Dark Splendid Reagan, que apresentaram maior número de tricomas. $\mathrm{mm}^{-2}$ de folha, quando comparadas com a cultivar Yellow Snowdon, foram as que apresentaram menor sobrevivência das ninfas. Segundo os autores a presença dos tricomas nas folhas, bem como o seu aspecto morfológico, exerceu efeito de resistência mecânica sobre as ninfas nos ínstares iniciais do desenvolvimento, uma vez que os autores observaram que as formas jovens demonstraram dificuldade para locomoção e para alimentação. Os autores mencionam, ainda, que a alta densidade de tricomas dificultou a penetração dos estiletes das ninfas no tecido das folhas e vasos do floema, inviabilizando o acesso ao alimento e ocasionando, conseqüentemente, uma baixa sobrevivência ninfal nos ínstares iniciais de desenvolvimento.

0 balanço de nutrientes nas plantas também é um fator muito importanteno desenvolvimento dos pulgões. Bernays e Chapman (1994) mencionam que os pulgões, por serem especializados na sucção 
de seiva do floema, são extremamente sensíveis a variações na concentração de aminoácidos, podendo, por exemplo, se desenvolver mais rapidamente em plantas com alto teor de asparagina e glutamina.

Uma combinação de características, provavelmente morfológicas e químicas, pode estar envolvida na resistência apresentada neste trabalho, pelos acessos de melancia 2, 10 e 25 ao pulgão A . gossypii. Futuros estudos poderiam investigar quais são essas características de resistência para que elas possam ser trabalhadas em programas de melhoramento genético, visando o desenvolvimento de genótipos de melancia mais resistentes ao ataque de A . gossypii.

Conforme demonstraram Pereira et al. (2003), a aplicação de inseticidas sistêmicos no controle de A . gossypii não reduz a incidência de viroses na cultura da melancia. Portanto, o uso de acessos resistentes de melancia, que afetem aspectos biológicos e reprodutivos dos afídeos, pode contribuir para a redução dos danos diretos provocados pela sucção dos pulgões e, talvez, contribuir para a redução na incidência de viroses na cultura.

Finalmente, vale ressaltar que o uso de plantas resistentes a insetos não onera o custo de produção, não oferece riscos para a saúde humana e animal, reduz perdas quantitativas e qualitativas, não polui o meio ambiente e é compatível com outras estratégias de controle dentro de um programa de MIP.

\section{CONCLUSÕES}

Todos os acessos de melancia avaliados nesta pesquisa apresentaram um certo grau de suscetibilidade ao ataque de A phis gossypii, porém nos acessos mais resistentes o número de ninfas por fêmea, após 24 horas de alimentação, foi menor.

\section{REFERÊNCIAS}

ALVES, A. B. Custo de produção e rentabilidade da melancia irrigada em Roraima. In: MEDEIROS, R. D.; HALFELD-VIEIRA, B. A. (Ed.). Cultura da melancia em Roraima. Brasília: Embrapa Informação Tecnológica, 2007. p. 116-125.

BERNAYS, E. A.; CHAPMAN, R. F. Host-plant selection by phytophagous insects. New York: Chapman \& Hall, 1994.

FERNANDES, A. M. V. et al. D esenvolvimento do pulgão A phis gossypii Glover (Hemiptera: A phididae) em três cultivares do algodão herbáceo $\mathrm{G}$ ossypium hirsutum L. r. latifolium Hutch. Neotrop. Entomol., Londrina, v. 30, n. 3, p. 467-470, 2001.

HALFELD-VIEIRA, B. A. et al. Identificação sorológica de espécies de Potyvirus em melancia, no estado de Roraima. Fitopat. Bras., Brasília, v. 29, n. 6, p. 687-689, 2004.

LARA, F. M. Princípios de resistência de plantas a insetos. São Paulo: Ícone, 1991.

MARSARO Jr., A. L.; PEREIRA, P. R. V. S.; MOREIRA, M. A. B. Insetos-praga associados à cultura da melancia, em Roraima, e alternativas de controle. In: MEDEIRO S, R. D.; HALFELD VIEIRA, B. A. (Ed.). Cultura da melancia em Roraima. Brasília: Embrapa, 2007. p. 64-86.

MEDEIRO S, R. D.; ALVES, A. B. Plantio e tratos culturais. In: MEDEIROS, R. D.; HALFELD VIEIRA, B. A. (Ed.). Cultura da melancia em Roraima. Brasília: Embrapa, 2007. p. 12-21.

MICHELOTTO, M. D.; SILVA, R. A.; BUSOLI, A. C. Aspectos reprodutivos de A phis gossypii Glover, 1877 (Hemiptera: A phididae) em três cultivares de algodoeiro e três espécies de plantas daninhas. Ciênc. Rural, Santa Maria, v. 33, n. 6, p. 999-1004, 2003.

PEREIRA, P. R. V. S.; NASCIMENTO, E. P.; DIAS, M. R. N. Insetos de importância econômica para a cultura da melancia. Comunicado Técnico, v. 1, n. 10, p. 16, 2002. 
PEREIRA, P. R. V. S. et al. Avaliação de inseticidas no controle de pragas da melancia Citrullus lanatus e seu impacto na incidência de viroses. Boletim de Pesquisa e Desenvolvimento, Boa Vista, v. 1, n. 2, p. 17, 2003.

SO GLIA, M. C. M.; BUENO, V. H. P.; SAMPAIO, M. V. D esenvolvimento e sobrevivência de A phis gossypii Glover (Hemiptera: Aphididae) em diferentes temperaturas e cultivares comerciais de crisântemo. N eotrop. Entomol., Londrina, v. 31, n. 2, p. 211-216, 2002.

VENDRAMIM, J. D.; NAKANO, O. Aspectos biológicos de A phis gossypii Glover, 1877 (Homoptera: Aphididae) em algodoeiro. An. Soc. Entomol. Bras., Londrina, v. 10, n. 2, p. 163-173, 1981.

Recebido: 03/ 04/ 2008

Received: 04/ 03/ 2008

Aprovado: 15/11/2008

A pproved: $11 / 15 / 2008$

Revisado: 19/08/2009

Reviewed: 08/ 19/2009 